\title{
A new marrellomorph euarthropod from the Early Ordovician of Argentina
}

María J. Aris, Jose A. Corronca, Sebastián Quinteros, and Paolo L. Pardo

Acta Palaeontologica Polonica 62 (1), 2017: 1-8 doi:http://dx.doi.org/10.4202/app.00240.2016

Marrellomorphs (class Marrellomorpha) are a group of Paleozoic arthropods with a very poor fossil record. Here we describe a new marrellomorph arthropod Mimetaster florestaensis sp. nov. from the Tremadocian (earliest Ordovician) of Argentina. The new species is characterized by the shape and direction of the three pairs of principal spines, and the existence of strong secondary spines only in the proximal two-thirds of the anterolateral spines. As a result of phylogenetic analysis the new species integrates a trichotomy with Mimetaster hexagonalis and a Moroccan unnamed marrellid as sister groups. This discovery increases the known diversity of Marrellomorpha and represents the first occurrence of this group in South America, expanding the spatial distribution of the clade.

Key words: Marrellida, Mimetasteridae, Tremadocian, Floresta Formation, Argentina, Salta.

María J. Aris [josefinaaris03@gmail.com], Cátedra de Paleontología, Consejo de Investigación de la Universidad Nacional de Salta (CIUNSa) and Instituto para el Estudio de la Biodiversidad de Invertebrados (IEBI), Facultad de Ciencias Naturales de la Universidad Nacional de Salta, Av. Bolivia 5150, CP 4400 Salta, Argentina. Jose A. Corronca [jcoronca@gmail.com] and Paolo L. Pardo [pardobio@gmail.com ], Instituto para el Estudio de la Biodiversidad de Invertebrados (IEBI) and Consejo Nacional de Investigaciones Científicas y Técnicas (CONICET), Facultad de Ciencias Naturales de la Universidad Nacional de Salta, Av. Bolivia 5150, CP 4400 Salta, Argentina. Sebastián Quinteros [squint@unsa.edu.ar], Consejo Nacional de Investigaciones Científicas y Técnicas (CONICET) and Instituto de Bio y Geociencias del NOA (IBIGEO), Facultad de Ciencias Naturales de la Universidad Nacional de Salta, Av. Bolivia 5150, CP 4400 Salta, Argentina.

This is an open-access article distributed under the terms of the Creative Commons Attribution License (for details please see creativecommons.org), which permits unrestricted use, 
distribution, and reproduction in any medium, provided the original author and source are credited.

Faf Full text $(682.0 \mathrm{kB})$ 